\title{
Involvement of Deep Eutectic Solvents in Extraction by Molecularly Imprinted Polymers-A Minireview
}

\author{
Michal Jablonský ${ }^{1, *}$, Veronika Majová ${ }^{1}$, Jozef Šima ${ }^{2}$, Katarína Hroboňová ${ }^{3}$ and \\ Anna Lomenová ${ }^{3}$ \\ 1 Institute of Natural and Synthetic Polymers, Department of Wood, Pulp and Paper, Faculty of Chemical and \\ Food Technology, Slovak University of Technology in Bratislava, Radlinskeho 9, SK-812 37 Bratislava, \\ Slovakia; veronika.majova@stuba.sk \\ 2 Department of Inorganic Chemistry, Faculty of Chemical and Food Technology, Slovak University of \\ Technology in Bratislava, Radlinskeho 9, SK-812 37 Bratislava, Slovakia; jozef.sima@stuba.sk \\ 3 Institute of Analytical Chemistry, Faculty of Chemical and Food Technology, Slovak University of \\ Technology in Bratislava, Radlinskeho 9, SK-812 37 Bratislava, Slovakia; \\ katarina.hrobonova@stuba.sk (K.H.); anna.lomenova@stuba.sk (A.L.) \\ * Correspondence: michal.jablonsky@stuba.sk
}

Received: 28 February 2020; Accepted: 18 March 2020; Published: 19 March 2020

\begin{abstract}
Substantial research activity has been focused on new modes of extraction and refining processes during the last decades. In this field, coverage of the recovery of bioactive compounds and the role of green solvents such as deep eutectic solvents (DESs) also gradually increases. A specific field of DESs involvement is represented by molecularly imprinted polymers (MIPs). The current state and prospects of implementing DESs in MIPs chemistry are, based on the accumulated experimental data so far, evaluated and discussed in this minireview.
\end{abstract}

Keywords: deep eutectic solvents; molecularly imprinted polymers; extraction

\section{Introduction}

Green chemistry and technologies related to it contribute to the improvement of the environment, and also provide a significant economic impact. Remarkable progress has been achieved, mainly in the area of seeking new methods of obtaining chemicals, in particular phytochemicals from plant materials, from natural renewable resources and from waste matter. The goal is to isolate the target compounds or substances selectively, and at the same time eliminate and remove undesirable by-products. Phytochemicals are part of a broad and diverse group of chemical compounds, classified according to their chemical structures and functional properties. As typical representatives, polyphenols, terpenes, amino acids, and proteins can be mentioned [1].

In order to extract desired substances, extraction techniques are currently used-among which the most widely utilized are Soxhlet extraction, accelerated solvent extraction, ultrasound-assisted extraction, microwave-assisted extraction and supercritical fluid extraction [2]. Target chemical compounds differ in their polarity, stability and physical properties, thus rendering a single-step extraction with one solvent for all the compounds from real plant materials generally impossible. To extract, separate and purify the desired substances, several organic solvents are commonly utilized. However, they are often volatile, toxic, flammable, explosive, and their biodegradability is low. That is the rationale behind innovative methods of extraction and separation of analytes in natural materials, which would reduce the consumption of organic solvents, and also improve the efficiency, selectivity and kinetics of extraction. Deep eutectic solvents (DESs) are such alternative solvents.

For isolating, purifying and pre-concentrating individual target substances from primary fractions of extracts, selective sorbents are suitable. Molecularly imprinted polymers (MIPs) have already proven 
the justification of their use in the isolation of the desired substances. To date, however, the benefits of the combination of DESs and MIPs have not been sufficiently recognized and exploited. The use of DES in MIP synthesis can eliminate some of the disadvantages of traditional procedures (e.g., high volumes of organic solvents) and improve properties of prepared sorbents.

The aim of this minireview is to point out examples of DES usage in MIP synthesis and on the applications of sorbents in extraction procedures for the isolation/purification of substances from complex matrices.

\section{Deep Eutectic Solvents}

Deep eutectic solvents are mixtures of two or more compounds-hydrogen bond donor (HBD) and hydrogen bond acceptor (HBA) — with a freezing point well below the melting point for any of the original mixture components. From the viewpoint of application, it is preferred that they are liquids at room temperature. The role of HBA is most frequently performed by quaternary ammonium chlorides such as choline chloride (further abbreviated as $\mathrm{ChCl}$ ) or by amino acids. Urea and imidazole derivatives, amides, alcohols, saccharides or organic carboxylic acids act as HBD. From the chemical point of view, the typical feature of DESs is that HBA and HBD are bonded by the hydrogen bond. When the compounds constituting a DES are exclusively primary metabolites, namely, amino acids, organic acids, sugars, or choline derivatives, the DESs are called natural deep eutectic solvents (NADES). There are also non-eutectic liquid mixtures referred to as low-transition temperature mixtures (LTTMs), composed of high-melting-point starting materials. Since the differences in the properties of the mentioned types of mixtures are from the practical point of view negligible, we will stick to the term DESs. Of the four DESs classes [3], we will mainly deal with the third class of DESs composed of organic constituents. It is worth pointing out that DESs should not be confused with ionic liquids, which are salts in the liquid state with the constituents bonded by the ionic bond.

In comparison with usual solvents, DESs provide many advantages, such as low volatility, low toxicity, miscibility with water, biocompatibility and biodegradability, and low price, and they are also easily prepared with a broad scale of polarity [4-6]. DESs based on $\mathrm{ChCl}$ and urea were invented in 2003 [7]. The assessment of their properties (density, viscosity, surface tension, refractive index, $\mathrm{pH}$, etc.) showed their potential to be utilized in industrial applications involving the production of materials with specific properties, the processing of complex materials, and the separation of components from complex mixtures [7].

One of the possibilities of application of DESs lies in obtaining phytochemical extracts for pharmaceutical industry. Another area is the isolation of compounds from biomass, which would be a useful tool for obtaining valuable resources (as raw materials for new products) for various industrial branches, including cosmetic and food industries. There are many combinations of compounds with donor-acceptor properties which may comprise eutectic systems. Besides appropriate physicochemical properties, DESs also offer another benefit-namely its liquid state in a broad interval of temperatures. Before using the prepared mixtures, it is necessary to evaluate the influence of the type and molar ratio of the components on the properties of DESs. Investigating the physical properties of DESs is very important, since they are relatively new systems and have not been examined enough yet. Viscosity and density belong to those properties which vary with temperature and are significant due to diverse applications of DESs $[5,8,9]$. DESs are often used in a mixture with water, which plays a remarkable role in overcoming the difficulties caused by highly viscous eutectic mixtures. By varying the ratio of HBA and HBD, it is possible to purposefully prepare specific DESs with predefined physicochemical properties, such as melting point, viscosity, conductivity and $\mathrm{pH}$, which are crucial in making the appropriate choices for targeted industrial applications.

\section{Extraction by Deep Eutectic Solvents}

Significant attention is currently paid to the utilization of DESs for isolating bioactive substances from various resources (biomass, biowaste, food-related waste, plant materials), the extraction of 
inorganic and organic substances from waste, and materials of biological origin [10]. Results of numerous studies have shown that the usage of "green" solvents often brings about higher extraction efficiency compared to the use of conventional solvents. In recent years, the effort of scientists and technologists has been directed to application of DESs in combination with modern extraction techniques [4,5,11], such as: ultrasound-assisted extraction (UAE) [12-15], negative pressure cavitation extraction (NPC) [13], enzyme assisted extraction (EAE) [3], supercritical fluid extraction (SFE) [16], microwave-assisted extraction (MAE) [9,11], microwave hydrothermal extraction [17], subcritical water extraction [18], and percolation extraction [14]. One of the most important classes of extractable target compounds is polyphenols, exhibiting antioxidant properties, radical scavenging activity, and pharmaceutical and beneficial medical effects [19]. Plant polyphenols comprise the most numerous and widespread group of natural substances isolated from materials of plant origin. Several papers focused on DESs-based extraction of polyphenols, especially flavonoids and phenolic acids from plants, such as Dictamnus albus, Foeniculum vulgare, Origanum majorana, mint, Salvia officinalis [20], Platycladi Cacumen [15], Sophora japonica [21], and others [4,5]. Duan et al. [22] tested five traditional Chinese plants, namely Berberidis Radix, Epimedii Folium, Notoginseng Radix et Rhizoma, Rhei Rhizoma et Radix, and Salviae Miltiorrhizae Radix et Rhizoma in order to evaluate the efficiency of 43 DESs in extraction of alkaloids, flavonoids, saponins, anthraquinones, and phenolic acids. As the results have shown, the extraction efficiency was influenced by all types of DESs. Icariin, a flavonoid, was effectively extracted with proline-containing DESs. Fu et al. [23] investigated the extraction of protocatechuic acid, catechins, epicatechin and caffeic acid from Trachycarpus fortune using DESs as the extraction medium. In order to prepare the DESs, $\mathrm{ChCl}$ was mixed with ethylene glycol, glycerol, xylitol, phenol, formic acid, citric acid, oxalic acid and malonic acid. Being environmentally friendly, with low vapor pressure, non-flammability and good thermal stability, DESs proved their high potential for the extraction and purification of polyphenols. The highest extraction yield of protocatechuic acid and epicatechin was achieved using a mixture of $\mathrm{ChCl}$ and formic acid in a 1:1 molar ratio at the extraction temperature of $40^{\circ} \mathrm{C}$ in a 6-h procedure [23]. Jeong et al. [24] tested $26 \mathrm{DESs}$, including 9 betaine-based DESs, 8 containing citric acid and 9 containing glycerols, in the process of extraction of catechin from green tea Camellia sinensis. Their results have shown that the mixture containing betaine, glycerol and glucose in molar ratio of 4:20:1 and a $\mathrm{pH}$ of 7.16 was the most suitable in comparison with other organic solvents. Škulcová et al. [25] applied various types of DESs to extract compounds from spruce bark (Picea abies). The overall content of polyphenols was determined using the method with Folin-Ciocalteu agent. The polyphenol content in eutectic extracts ranged from 41 to $463 \mathrm{mg}$ of gallic acid equivalent to $100 \mathrm{~g}$ of extract. The results of extraction of particular compounds have been thoroughly described in several other publications, as well as in papers by members of the research team $[4,26]$. The utilization of DESs in polymer synthesis is a new and rapidly developing application area, too. DESs can be used in several phases in the processing, dissolving, extraction, synthesis, and modification of polymers. In recent years, a growing interest concerning DESs' role in the preparation of selective sorbents based on polymers with molecule-imprinted polymers, as well as the utilization of sophisticated approaches towards the molecularly imprinted polymer design, which can significantly reduce the time and cost in optimizing their production.

\section{Selective Sorbents Based on Molecularly Imprinted Polymers}

Molecularly imprinted polymers (MIPs) are synthetic tailor-made materials with a pre-defined selectivity for a template (frequently target compound), or closely related compounds for which they were designed. These materials are obtained by polymerizing functional and cross-linking monomers around a template molecule, which lead to a highly cross-linked three-dimensional network polymer (Figure 1). 


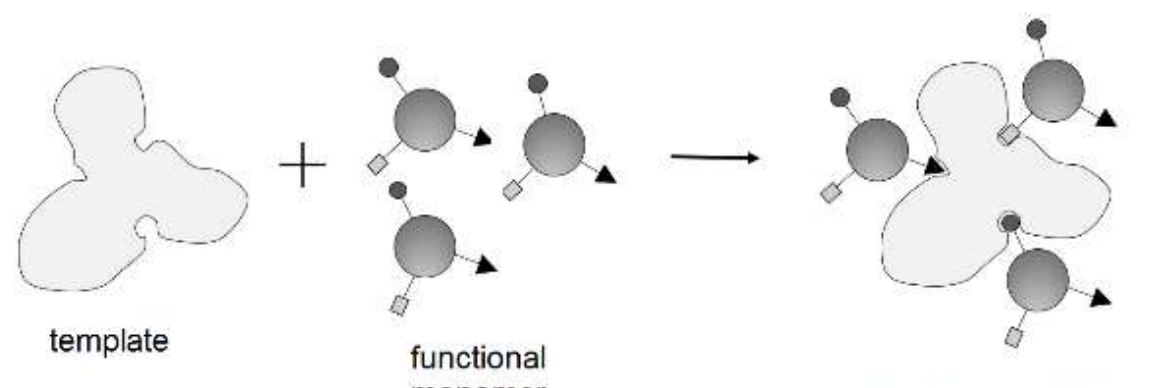

monomer

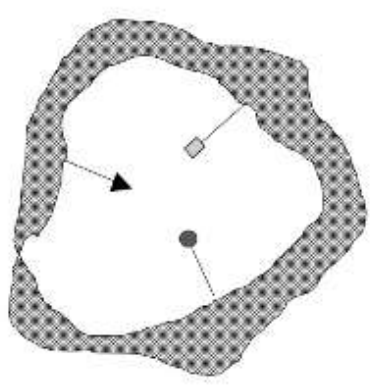

molecularly imprinted polymer

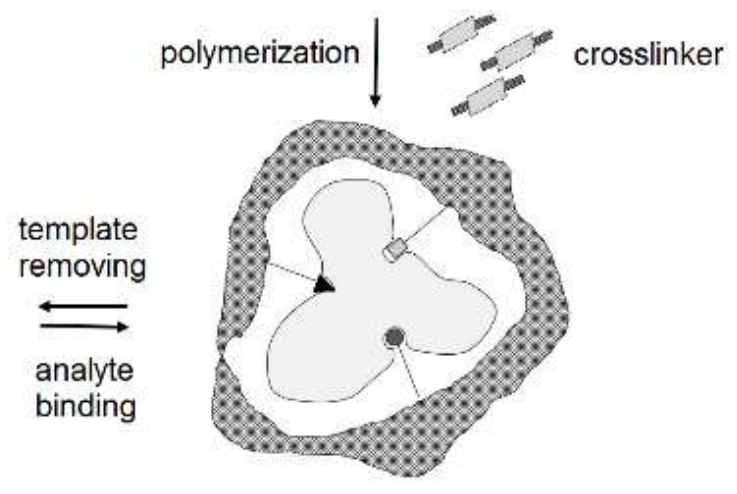

polymer with template

Figure 1. Scheme of MIP preparation [27].

The monomers are selected according to their ability to interact with the functional groups of the template molecule. After polymerization, the template molecules are extracted/removed from the polymeric matrix and binding sites, having their shape, size, and functionalities complementary to the target molecule established. Cavities are able to specifically recognize the target molecule in complex mixtures. The resulting polymers are stable, robust and resistant to organic solvents, high temperatures, and a wide range of $\mathrm{pH}$. In the most common method of preparation, monomers form a complex with a template through covalent or non-covalent interactions. The advantages of the non-covalent approach are the easy formation of the template-monomer complex, the easy removal of the templates from the polymers, fast binding of templates to MIPs and the possibility to prepare for a wide variety of compounds. MIPs are widely applied in the separation, cleaning and pre-concentration of compounds. Conventional MIPs preparation techniques include polymerization in block, precipitation, emulsion, multistep, swelling, suspension and other types of polymerization. The obtained particle size can vary from nano- to micro-particles, from irregular to spherical particles [27,28]. Despite the many advantages of MIPs — such as selectivity, sorption properties, and robustness-they also have disadvantages. When conventional techniques are used, the high quantities of organic solvents as porogens are consumed in preparation process. Water is rarely used, because it can form strong interactions with the template and/or the monomers, and thus destabilize complex formation and also interfere in the formation of specific imprinting sites. Details on the synthesis of MIPs are given elsewhere [29-31]. The use of DESs is an alternative and "green" strategy in MIP preparation, which can eliminate some disadvantages of traditional techniques and solvents. The relationship between DESs and MIPs can be realized in three ways: 1) the usage of a DES in a MIP preparation with the DES acting as a medium/porogen or a reactant incorporated in the MIP; 2) the use of a DES for biomass extraction with subsequent isolation of target compound(s) from the extract by a MIP; 3) the use of a DES as solvent for the extraction of target compound(s) from MIP. While there are a number of examples that meet point 1 (see Table 1), data to meet points 2 and 3 are very rare. In MIPs preparation methodologies, the DESs can be applied as medium or porogen, functional monomer [32-34], MIPs modifier [35,36], or MIPs template $[33,37]$. Such systems will be abbreviated as DES-MIPs. Some authors postulated 
that the interaction of a DES with the functional monomer, and/or the surface of a MIP improved the affinity, selectivity and adsorption of target compounds. Such systems will be abbreviated as DES-MIPs. Many publications showed that produced DES-MIPs were suitable for the specific and selective recognition of target compounds in real samples and were characterized by stability, reusability, a high imprinting factor, fast binding kinetics, and high adsorption capacity [38-40]. Some authors also reported the advantages of the DES-MIPs in comparison with MIPs from conventional monomers. The advantages of DESs as monomer compared with conventional monomers are due to their high content of functional groups, allowing unique interactions with template molecules, which result in the higher affinity and selectivity of DES-MIPs. A further advantage is the higher rigidity of DES-MIPs, which can prevent their shrinkage or swelling. Moreover, the liquid phase of DES is advantageous in including the monomer in the bulk of DES or by substituting the media or solvent $[36,38,41]$.

Table 1. The application of deep eutectic solvents (DESs) for molecularly imprinted polymers (MIPs) preparation and extraction/purification procedures.

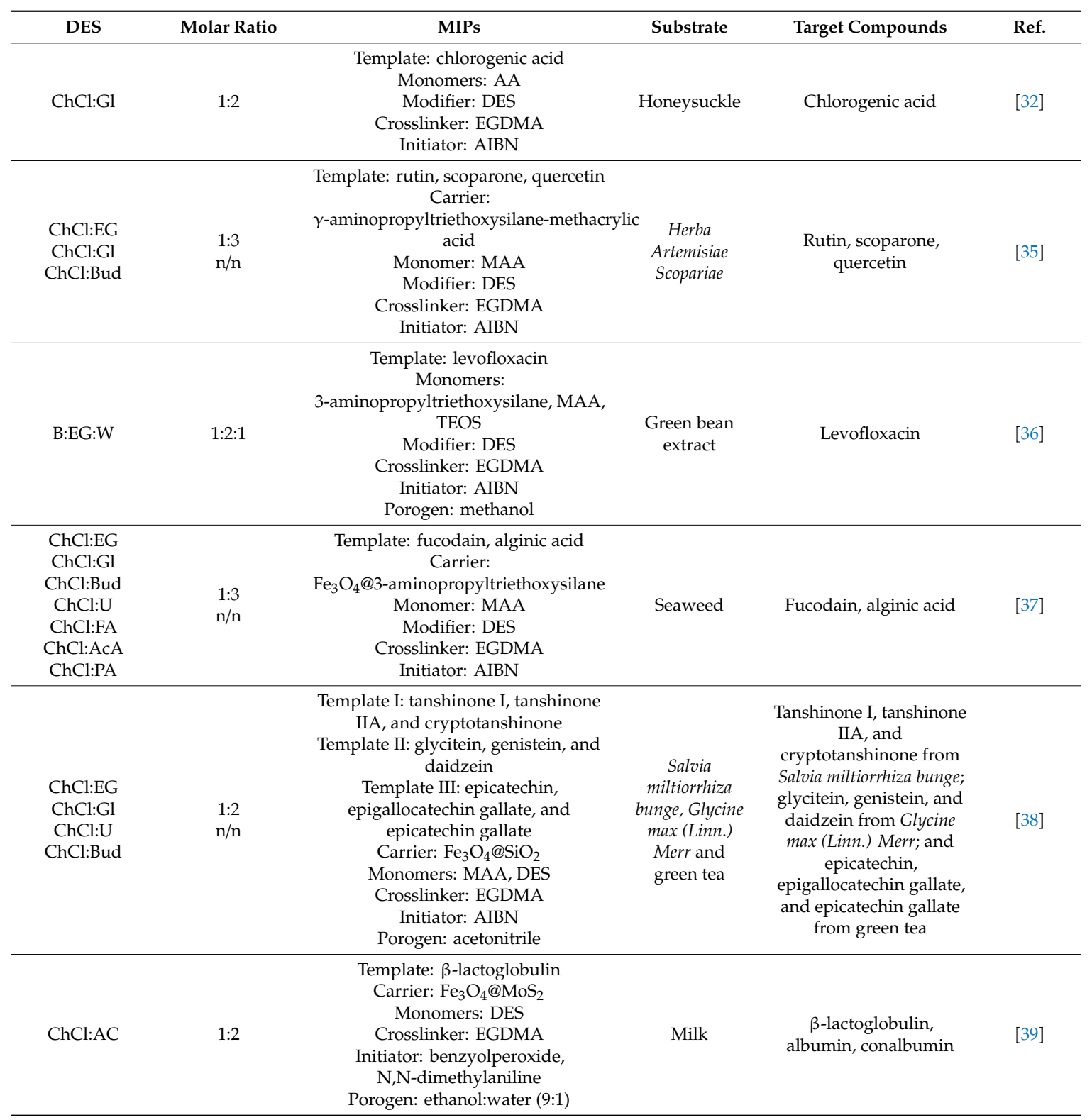


Table 1. Cont.

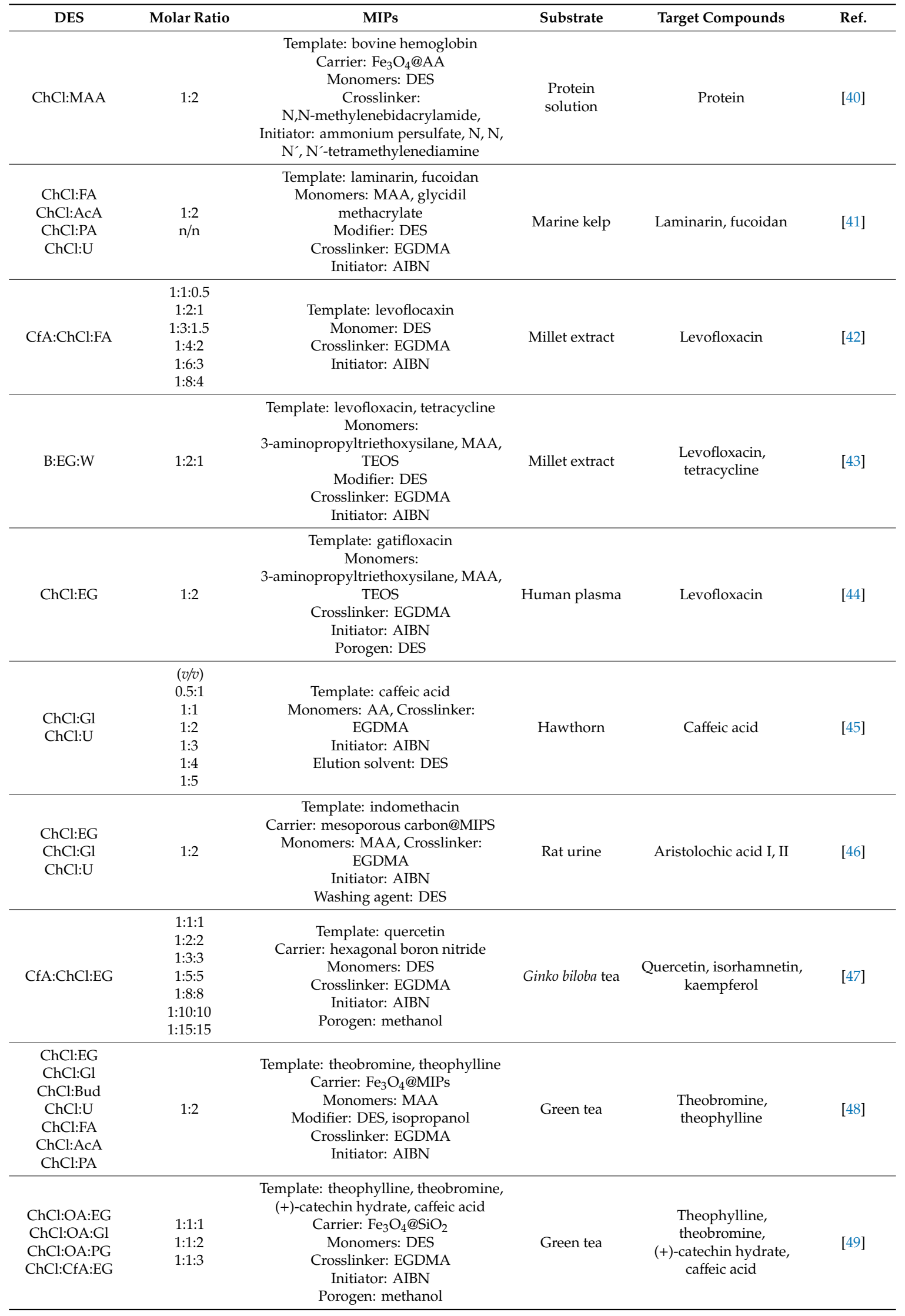


Table 1. Cont.

\begin{tabular}{|c|c|c|c|c|c|}
\hline DES & Molar Ratio & MIPs & Substrate & Target Compounds & Ref. \\
\hline $\begin{array}{l}\text { ChCl:EG } \\
\text { ChCl:Gl } \\
\text { ChCl:PG }\end{array}$ & $1: 1$ & $\begin{array}{l}\text { Template: chloramphenicol } \\
\text { Monomers: AA } \\
\text { Auxiliary monomer: DES } \\
\text { Crosslinker: divinilbenzene } \\
\text { Initiator: AIBN } \\
\text { Porogen: acetonitrile }\end{array}$ & Milk & Chloramphenicol & {$[50]$} \\
\hline
\end{tabular}

The actual researches are focused on new innovative approaches in DES-MIPs preparations. DES-MIPs were prepared on the surface of carrier material (magnetite), using $\mathrm{ChCl}$ and acrylic acid (1:2) as a functional monomer. This experimental approach avoids the immersion of the template during polymerization and facilitates its removal [33]. Extraction, including solid phase extraction, is a very complex process. For a better understanding of the adsorption of the adsorbate, investigation of the adsorption kinetics is useful. Moreover, the kinetic parameters are useful for designing and modeling the adsorption process, since they can provide information on the number of adsorbed molecules during the adsorption process. To investigate the kinetics of the adsorption process, the pseudo-first order, pseudo-second order models, and intraparticle diffusion model are used [38,39]. The latest results published in the last five years and evaluating the state-of-the-art of methods and technologies applied in the field of DES-MIPs utilization document a wide potential range of these systems in obtaining and/or purifying value-added substances [32,35-51] (Table 1). Extraction methods using DES-MIPs show excellent adsorption ability and selectivity for the selection of templates or target compounds in case studies. In these studies, $\mathrm{ChCl}$ acts as $\mathrm{HBA}$ in binary or ternary $\mathrm{ChCl}$-based DESs. Research groups of $\mathrm{Li}$ and Row $[36,43]$ applied the ternary system containing betaine (HBA), ethylene glycol and water (1:2:1) for extraction of levofloxacin, tetracycline from millet extract [43] and levofloxacin from green bean [36]. Levofloxacin as the target compound was isolated from green been with the recovery reaching 95.2\% [36]. From millet, levofloxacin (94.5\%), and tetracycline (93.3\%), were extracted [43]. Li and Row [42] also studied the application of ternary systems and DES containing caffeic acid: $\mathrm{ChCl}$ formic acid in a different molar ratio, and this system as a functional monomer in MIP synthesis. Polymeric sorbent was applied for the purification of levofloxacin. Recovery of levofloxacin for different DES-MIPs (molar ratio for DES: 1:1:0.5; 1:2:1; 1:3:1.5) ranged from $83.2 \%$ to $91.3 \%$. Hybrid monomer $\gamma$-aminopropyltriethoxysilane-methacrylic acid (KH-550-MAA) was modified by DESs composed of $\mathrm{ChCl}$ and ethylene glycol, glycerol or 1,4-butanediol acting as HBD with template (target compound) rutin, scoparone, quercetin were evaluated as more effective from the viewpoint of recoveries of the target compounds compared with hybrid molecular imprinted polymers (HMIPs) modified with ionic liquids [35]. Modified by DES and ionic liquids, the HMIPs were developed for high recognition towards rutin, scoparone, and quercetin in Herba Artemisiae Scopariae. The best extraction recoveries were found for the system $\mathrm{ChCl}$ :glycerol (1:3)-HMIPs (rutin $92.27 \%$; scoparone $87.51 \%$; quercetin $80.02 \%$ ). The attention of the authors of papers $[50,51]$ was focused on milk analysis with DES-MIPs. A molar ratio of 1:1 of a mixture of ChCl:ethylene glycol, ChCl:glycerol, or ChCl:propylene glycol [50] or a mixture of $\mathrm{ChCl}$ :glycerol (1:2, n/n) [51], with template chloramphenicol, were used in DES-MIPs preparation for milk analysis. These sorbents were applied for extraction of chloromycetin (CHL) and thiamphenicol (THI), which are still used illegally in some animals intended for food production all over the world. DES-MIPs in dispersive liquid-liquid microextraction or in solid-phase extraction show higher recoveries for both analytes/templates ( $87.23 \%$ for CHL; $83.17 \%$ for THI $/ 91.23 \%$ for CHL; $87.02 \%$ for THI, respectively) than MIPs prepared without DES. 
The purification of hawthorn extract was achieved by solid-phase extraction process, and SPE recoveries of chlorogenic acid were $72.56 \%, 64.79 \%, 69.34 \%$ and $60.08 \%$ by DES-MIPs, DES-NIPs, MIPs and NIPs, respectively [32]. Non imprinted polymers (NIPs) are synthesized and treated under the same conditions but without the addition of the template. The results showed that strategy of modification of different systems (MIPs) by DES led to improving the properties of polymers due to the controlled morphology and homogeneity of the binding sites. In addition to the possibilities offered by MIPs and DES-MIPs, invention of a new class of MIPs-magnetic MIP (further on MMIPs)-has opened and expanded the possibilities of extraction, isolation and analysis of the desired compounds from materials of biological origin as well as separation of MIPs from reaction systems. DES-MMIPs can contain various magnetic parts as carrier, such as $\mathrm{Fe}_{3} \mathrm{O}_{4} @ 3$-aminopropyltriethoxysilane [37], $\mathrm{Fe}_{3} \mathrm{O}_{4} @ \mathrm{SiO}_{2}$ [38]; $\mathrm{Fe}_{3} \mathrm{O}_{4} @ \mathrm{MoS}_{2}$ [39]; $\mathrm{Fe}_{3} \mathrm{O}_{4} @$ acrylic acid [40]; $\mathrm{Fe}_{3} \mathrm{O}_{4}$ [48]; $\mathrm{Fe}_{3} \mathrm{O}_{4} @ S \mathrm{SiO}_{2}$ [49]. MIPs are imprinted on the surface of magnetic parts and have usually a core-shell structure, of which the magnetic phase is the core and the polymeric phase acts as the shell [31]. One of the advantages of MMIPs lies in the fact that after the extraction or elution, particles can be easily separated using an external magnetic field rather than centrifugation or filtration. Fu et al. [39] have renewed and reinforced the interest in the recovery of proteins such as $\beta$-lactoglobulin, albumin, conalbumin from milk. The resulting magnetic polymer poly(ChCl-acrylic acid) $\mathrm{Fe}_{3} \mathrm{O}_{4} @ \mathrm{MoS}_{2}$ was in the form of nanospheres. It was characterized by good thermal stability at room temperature, and good adsorption capacity and selectivity for $\beta$-lactoglobulin. The strong antibacterial activity of this material was confirmed vs. S. aureus, E. coil and B. subtilis. In the case study [38], MMIPs containing $\mathrm{Fe}_{3} \mathrm{O}_{4} @ \mathrm{SiO}_{2}$ were used. The MIP layer was produced using methacrylic acid (MAA) as a monomer, with the following DESs as porogens:ChCl:urea (DES1); ChCl:ethylene glycol (DES2); ChCl:1,4-butanediol (DES3) and ChCl: glycerol (DES4). Ethylene glycol dimethacrylate (EGDMA) acted as the crosslinker, and 2,2-azobisisobutyronitrile (AIBN) as the initiator. The template role was performed by template I: tanshinone I, tanshinone IIA, or cryptotanshinone; template II: glycitein, genistein, or daidzein; template III: epicatechin, epigallocatechin gallate, or epicatechin gallate. In this study, systems for the extraction of substances from different substrates (Salvia miltiorrhiza bunge, Glycine max (Linn.) Merr and green tea) by non-DES-MNIP, non-DES-MMIP, DES1-MMIP, DES2-MMIP, DES3-MMIP, DES4-MMIP were compared. The system DES4-MMIP showed the best extraction ability for various substances and substrate. Extraction recoveries reached $85.57 \%$ for tanshinone I, $80.58 \%$ for tanshinone IIA, $92.12 \%$ for cryptotanshinone, $81.65 \%$ for glycitein, $87.72 \%$ for genistein, $92.24 \%$ for daidzein, $86.43 \%$ for epicatechin, $80.92 \%$ for epigallocatechin gallate, and $93.64 \%$ for epicatechin gallate. Furthermore, it was observed that DES-containing polymers showed higher selectivity for nine targets than that of systems without the DESs (for both MMIP and MNIP). It was documented that the MMIPs modified by DES are an innovative approach for the extraction of target substances with a higher selectivity and efficiency in the extraction of target compounds. These results of selective recognition and higher recoveries of polysaccharides were also confirmed in another study using seaweed as a substrate [37]. Taking $\mathrm{Fe}_{3} \mathrm{O}_{4} @ 3$-aminopropyltriethoxysilane as a carrier; fucodain and alginic acid as templates; MMA as a monomer; EGDMA as a crosslinker, and AIBN as an initiator, the MMIPs were modified by the DESs-ChCl:ehylene glycol; ChCl:glycerol; ChCl:1,4-butanediol; ChCl:urea; ChCl:formic acid; $\mathrm{ChCl}$ acetic acid; and $\mathrm{ChCl}$ :propionic acid-were prepared [37]. The selective recognition and separation of proteins by DES-MMIPs was evaluated by Liu et al. [40]. The DES-MMIPs were produced using carrier $\mathrm{Fe}_{3} \mathrm{O}_{4} @$ acrylic acid, $\mathrm{ChCl}$ and methacrylic acid as a monomer, $\mathrm{N}, \mathrm{N}$-methylenebidacrylamide as crosslinker, ammonium persulfate, $\mathrm{N}, \mathrm{N}, \mathrm{N}^{\prime}, \mathrm{N}^{\prime}$-tetramethylenediamine as polymerization initiator, and bovine hemoglobin as a template. The adsorption capacity of the DES-MMIPs and DES-MNIPs with a different amount of monomer were compared, and the results suggested that DES-MIPs had approximately three times higher absorption capacity than DES-MNIPs. The extraction method using DES-MMIPs for the determination of target compounds from green tea was used with carriers $\mathrm{Fe}_{3} \mathrm{O}_{4} @$ MIPs [48] and $\mathrm{Fe}_{3} \mathrm{O}_{4} @ \mathrm{SiO}_{2}$ [49]. In the case of $\mathrm{Fe}_{3} \mathrm{O}_{4} @$ MIPs [48], MIPs modified by binary DESs such as ChCl:ehylene glycol; ChCl:glycerol; $\mathrm{ChCl}$ : 1,4-butanediol, $\mathrm{ChCl}$ :urea, $\mathrm{ChCl}$ :formic acid, 
$\mathrm{ChCl}$ :acetic acid, $\mathrm{ChCl}$ :propionic acid were used. The authors of the paper [49] described magnetic polymers modified by ternary DESs, namely $\mathrm{ChCl}$ :oxalic acid:ethylene glycol; $\mathrm{ChCl}$ :oxalic acid:glycerol; $\mathrm{ChCl}$ :oxalic acid:propylene glycol; $\mathrm{ChCl}$ :caffeic acid:ethylene glycol. The resulting modified polymers showed excellent adsorption ability and selectivity. The best system for the extraction of the target substances theophylline, theobromine, (+)-catechin hydrate, and caffeic acid from green tea [49] was $\mathrm{Fe}_{3} \mathrm{O}_{4}$-ChCl:oxalic acid:polypropylene glycol-MMIPs (5.82; 4:32; 18.36 and $3.96 \mathrm{mg} / \mathrm{g}$, respectively). For the binary system [48], $\mathrm{ChCl}$ : urea, and $\mathrm{Fe}_{3} \mathrm{O}_{4} @ \mathrm{MMIPs}$ [48], the extraction amounts of theobromine and theophylline reached $4.87 \mathrm{mg} / \mathrm{g}$ and $5.07 \mathrm{mg} / \mathrm{g}$ green tea, respectively.

\section{Conclusions}

This minireview is focused on the application of deep eutectic solvents (DESs) for the preparation of molecularly imprinted polymers (MIPs). DESs have been designed as an environmentally friendly option for the preparation of MIPs and MMIPs, since these solvents can improve the affinity and selectivity of polymers to a target substance. The actual research showed some innovative approaches in DES-MIPs, or DES-MMIPs preparations and utilization. The applications of DES in the production of MIPs are either as a medium or solvent, as functional monomers, as MIPs modifiers, or as MIPs templates in the processes of extraction, separation or purification technologies. In the production of MIPs, the employment of DESs is based on their use as functional monomers, MIPs modifiers, and MIPs templates, as well as in extraction, separation or purification procedures.

Even though the role of DESs in molecularly imprinted technology is still largely unexplored, a rapid increase in research and the implementation of results can be expected. In particular, the use of these solvents in the production of MIPs can—to a considerable extent-expand their use as a new breakthrough technology in greener separation and analytical techniques.

Author Contributions: M.J., K.H. and J.Š. contributed equally to the conceptualization and design of the work; writing—original draft preparation: M.J., J.Š., V.M., K.H., A.L.; writing—editing: M.J., J.Š., and K.H.; supervision and critical revision of the manuscript: M.J., J.Š.; project administration: M.J.; funding acquisition: M.J. All authors have read and agreed to the published version of the manuscript.

Funding: This work was supported by the Slovak Research and Development Agency under the contracts Nos. APVV-15-0052, APVV-19-0185, APVV-19-0174 and VEGA 1/0403/19, VEGA 1/0412/20. This article was realized also thanks to the support for infrastructure equipment provided by the Operation Program Research and Development for the project "National Center for Research and Application of renewable energy sources" (ITMS 26240120016, ITMS 26240120028), for the project "Competence center for new materials, advanced technologies and energy" (ITMS 26240220073), and for the project “University science park STU Bratislava" (ITMS 26240220084), co-financed by the European Regional Development Fund.

Acknowledgments: The authors would like to acknowledge the financial support of the Slovak Research and Development Agency and support for infrastructure equipment provided by the Operation Program Research and Development.

Conflicts of Interest: The authors declare no conflict of interest. The funders had no role in the design of the study; in the collection, analyses, or interpretation of data; in the writing of the manuscript, or in the decision to publish the results.

$\begin{array}{ll}\text { Abbreviations } \\ \text { AA } & \text { acrylamide } \\ \text { AC } & \text { acrylic acid } \\ \text { AcA } & \text { acetic acid } \\ \text { AIBN } & \text { 2,2-azobisisobutyronitrile } \\ \text { B } & \text { Betaine } \\ \text { Bud } & \text { 1,4-butanediol } \\ \text { CfA } & \text { caffeic acid } \\ \text { ChCl } & \text { choline chloride } \\ \text { CHL } & \text { chloromycetin } \\ \text { DES } & \text { deep eutectic solvent } \\ \text { EG } & \text { ethylene glycol } \\ \text { EGDMA } & \text { ethylene glycol dimethacrylate }\end{array}$




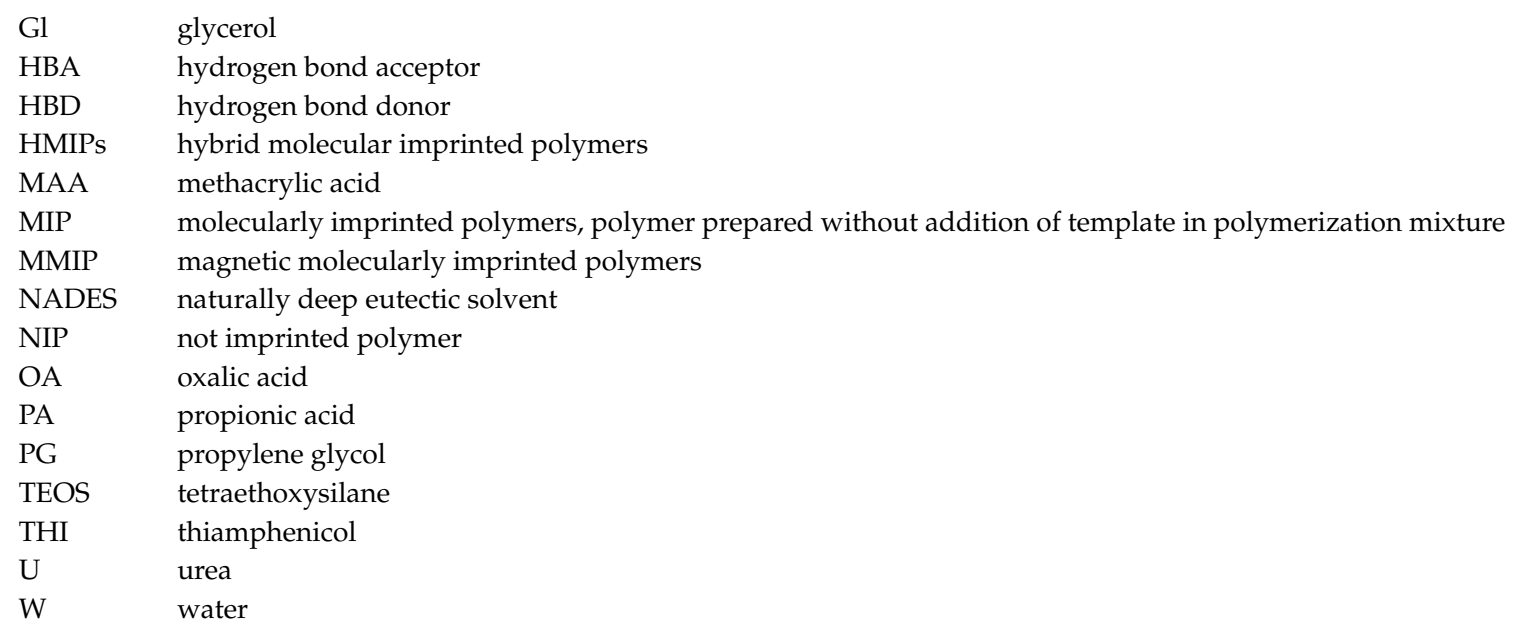

\section{References}

1. Mendonça, P.V.; Lima, M.S.; Guliashvili, T.; Serra, A.C.; Coelho, J.F.J. Deep eutectic solvents (DES): Excellent green solvents for rapid SARA ATRP of biorelevant hydrophilic monomers at ambient temperature. Polymer 2017, 132, 114-121. [CrossRef]

2. Raks, V.; Al-Suod, H.; Buszewski, B. Isolation, separation, and preconcentration of biologically active compounds from plant matrices by extraction techniques. Chromatographia 2018, 81, 189-202. [CrossRef] [PubMed]

3. Smith, E.L.; Abbott, A.P.; Ryder, K.S. Deep eutectic solvents (DESs) and their applications. Chem. Rev. 2014, 114, 11060-11082. [CrossRef] [PubMed]

4. Jablonsky, M.; Skulcova, A.; Malvis, A.; Sima, J. Extraction of value- added components from food industry based and agro-forest biowastes by deep eutectic solvents. J. Biotechnol. 2018, 282, 46-66. [CrossRef]

5. Jablonský, M.; Šima, J. Deep Eutectic Solvents in Biomass Valorization; Spektrum STU: Bratislava, Slovakia, 2019; p. 176.

6. Jablonský, M.; Škulcová, A.; Šima, J. Use of deep eutectic solvents in polymer chemistry-A review. Molecules 2019, 24, 3978. [CrossRef]

7. Abbott, A.P.; Capper, G.; Davies, D.L.; Rasheed, R.K.; Tambyrajah, V. Novel solvent properties of choline chloride/urea mixtures. Chem. Commun. 2003, 1, 70-71. [CrossRef]

8. Jablonsky, M.; Haz, A.; Majova, V. Assessing the opportunities for applying deep eutectic solvents for fractionation of beech wood and wheat straw. Cellulose 2019, 26, 7675-7684. [CrossRef]

9. Jablonsky, M.; Majova, V.; Ondrigova, K.; Sima, J. Preparation and characterization of physicochemical properties and application of novel ternary deep eutectic solvents. Cellulose 2019, 26, 3031-3045. [CrossRef]

10. Shishov, A.; Bulatov, A.; Locatelli, M.; Carradori, S.; Andruch, V. Application of deep eutectic solvents in analytical chemistry. A review. Microchem. J. 2017, 135, 33-38. [CrossRef]

11. Ekezie, F.G.C.; Sun, D.W.; Cheng, J.H. Acceleration of microwave-assisted extraction processes of food components by integrating technologies and applying emerging solvents: A review of latest developments. Trends Food Sci. Technol. 2017, 67, 160-172. [CrossRef]

12. Chen, Z.; Wan, C. Ultrafast fractionation of lignocellulosic biomass by microwave-assisted deep eutectic solvent pretreatment. Bioresour. Technol. 2018, 250, 532-537. [CrossRef] [PubMed]

13. Bajkacz, S.; Adamek, J. Evaluation of new natural deep eutectic solvents for the extraction of isoflavones from soy products. Talanta 2017, 168, 329-335. [CrossRef] [PubMed]

14. Bosiljkov, T.; Dujmić, F.; Bubalo, M.C.; Hribar, J.; Vidrih, R.; Brnčić, M.; Zlatic, E.; Redovniković, I.R.; Jokić, S. Natural deep eutectic solvents and ultrasound-assisted extraction: Green approaches for extraction of wine lees anthocyanins. Food Bioprod. Process. 2017, 102, 195-203. [CrossRef]

15. Zhuang, B.; Dou, L.-L.; Li, P.; Liu, E.-H. Deep eutectic solvents as green media for extraction of flavonoid glycosides and aglycones from Platycladi Cacumen. J. Pharm. Biomed. 2017, 134, 214-219. [CrossRef]

16. Paulaitis, M.; Krukonis, V.J.; Kurnik, R.T.; Reid, R.C. Supercritical fluid extraction. Rev. Chem. Eng. 1983, 1, 179-250. 
17. Yiin, C.L.; Quitain, A.T.; Yusup, S.; Sasaki, M.; Uemura, Y.; Kida, T. Characterization of natural low transition temperature mixtures (LTTMs): Green solvents for biomass delignification. Bioresour. Technol. 2016, 199, 258-264. [CrossRef]

18. Zhang, Y.; Zhang, Y.; Taha, A.A.; Ying, Y.; Li, X.; Chen, X.; Ma, C. Subcritical water extraction of bioactive components from ginseng roots (Panax ginseng CA Mey). Ind. Crop. Prod. 2018, 117, 118-127. [CrossRef]

19. Abbas, M.; Saeed, F.; Anjum, F.M.; Afzaal, M.; Tufail, T.; Bashir, M.S.; Ishtiaq, A.; Hussain, S.; Suleria, H.A.R. Natural polyphenols: An overview. Int. J. Food Prop. 2017, 20, 1689-1699. [CrossRef]

20. Bakirtzi, C.; Triantafyllidou, K.; Makris, D.P. Novel lactic acid-based natural deep eutectic solvents: Efficiency in the ultrasound-assisted extraction of antioxidant polyphenols from common native Greek medicinal plants. J. Appl. Res. Med. Arom. Plants 2016, 3, 120-127. [CrossRef]

21. Zhao, B.-Y.; Xu, P.; Yang, F.-X.; Wu, H.; Zong, M.-H.; Lou, W.-Y. Biocompatible deep eutectic solvents based on choline chloride: Characterization and application to the extraction of rutin from Sophora japonica. ACS Sustain. Chem. Eng. 2015, 3, 2746-2755. [CrossRef]

22. Duan, L.; Dou, L.-L.; Guo, L.; Li, P.; Liu, E.-H. Comprehensive evaluation of deep eutectic solvents in extraction of bioactive natural products. ACS Sustain. Chem. Eng. 2016, 4, 2405-2411. [CrossRef]

23. Fu, N.; Lv, R.; Guo, Z.; Guo, Y.; You, X.; Tang, B.; Han, D.; Yan, H.; Row, K.H. Environmentally friendly and non-polluting solvent pretreatment of palm samples for polyphenol analysis using choline chloride deep eutectic solvents. J. Chromatogr. A 2017, 1492, 1-11. [CrossRef] [PubMed]

24. Jeong, K.M.; Ko, J.; Zhao, J.; Jin, Y.; Han, S.Y.; Lee, J. Multi-functioning deep eutectic solvents as extraction and storage media for bioactive natural products that are readily applicable to cosmetic products. J. Clean. Prod. 2017, 151, 87-95. [CrossRef]

25. Škulcova, A.; Haščičová, Z.; Hrdlička, L.; Šima, J.; Jablonský, M. Green solvents based on choline chloride for the extraction of spruce bark (Picea abies). Cell. Chem. Technol. 2017, 52, 3-4.

26. Jablonský, M.; Škulcová, A.; Kamenská, L.; Vrška, M.; Šima, J. Deep eutectic solvents: Fractionation of wheat straw. BioResources 2015, 10, 8039-8047. [CrossRef]

27. Lomenova, A.; Hroboňová, K. Polyméry s odtlačkami molekúl ako chirálne stacionárne fázy v HPLC. Chem. Listy 2019, 113, 156-164.

28. Machyňáková, A.; Hroboňová, K. Možnosti prípravy polymérov s odtlačkami molekúl. Chem. Listy 2016, 110, 609-615.

29. BelBruno, J.J. Molecularly imprinted polymers. Chem. Rev. 2018, 119, 94-119. [CrossRef]

30. Cormack, P.A.; Elorza, A.Z. Molecularly imprinted polymers: Synthesis and characterisation. J. Chromatogr. B 2004, 804, 173-182. [CrossRef]

31. Huang, S.; Xu, J.; Zheng, J.; Zhu, F.; Xie, L.; Ouyang, G. Synthesis and application of magnetic molecularly imprinted polymers in sample preparation. Anal. Bioanal. Chem. 2018, 410, 3991-4014. [CrossRef]

32. Li, G.; Wang, W.; Wang, Q.; Zhu, T. Deep eutectic solvents modified molecular imprinted polymers for optimized purification of chlorogenic acid from honeysuckle. J. Chromatogr. Sci. 2016, 54, 271-279. [CrossRef] [PubMed]

33. Fu, N.; Li, L.; Liu, X.; Fu, N.; Zhang, C.; Hu, L.; Li, D.; Tang, B.; Zhu, T. Specific recognition of polyphenols by molecularly imprinted polymers based on a ternary deep eutectic solvent. J. Chromatogr. A 2017, 1530, 23-34. [CrossRef] [PubMed]

34. Ma, W.; Dai, Y.; Row, K.H. Molecular imprinted polymers based on magnetic chitosan with different deep eutectic solvent monomers for the selective separation of catechins in black tea. Electrophoresis 2018, 39, 2039-2046. [CrossRef] [PubMed]

35. Li, G.; Ahn, W.S.; Row, K.H. Hybrid molecularly imprinted polymers modified by deep eutectic solvents and ionic liquids with three templates for the rapid simultaneous purification of rutin, scoparone, and quercetin from Herba Artemisiae Scopariae. J. Sep. Sci. 2016, 39, 4465-4473. [CrossRef] [PubMed]

36. Li, X.; Row, K.H. Application of deep eutectic solvents in hybrid molecularly imprinted polymers and mesoporous siliceous material for solid-phase extraction of levofloxacin from green bean extract. Anal. Sci. 2017, 33, 611-617. [CrossRef]

37. Li, G.; Row, K.H. Magnetic molecularly imprinted polymers for recognition and enrichment of polysaccharides from seaweed. J. Sep. Sci. 2017, 40, 4765-4772. [CrossRef] 
38. Li, G.; Wang, X.; Row, K.H. Magnetic molecularly imprinted polymers based on silica modified by deep eutectic solvents for the rapid simultaneous magnetic-based solid-phase extraction of Salvia miltiorrhiza bunge, Glycine max (Linn.) Merr and green tea. Electrophoresis 2018, 39, 1111-1118. [CrossRef]

39. Fu, N.; Li, L.; Liu, K.; Kim, C.K.; Li, J.; Zhu, T.; Li, J.; Tang, B. A choline chloride-acrylic acid deep eutectic solvent polymer based on $\mathrm{Fe}_{3} \mathrm{O}_{4}$ particles and $\mathrm{MoS}_{2}$ sheets (poly (ChCl-AA DES)@ $\mathrm{Fe}_{3} \mathrm{O}_{4} @ \mathrm{MoS}_{2}$ ) with specific recognition and good antibacterial properties for $\beta$-lactoglobulin in milk. Talanta 2019, 197, 567-577. [CrossRef]

40. Liu, Y.; Wang, Y.; Dai, Q.; Zhou, Y. Magnetic deep eutectic solvents molecularly imprinted polymers for the selective recognition and separation of protein. Anal. Chim. Acta 2016, 936, 168-178. [CrossRef]

41. Li, G.; Dai, Y.; Wang, X.; Row, K. Molecularly imprinted polymers modified by deep eutectic solvents and ionic liquids with two templates for the simultaneous solid-phase extraction of fucoidan and laminarin from marine kelp. Anal. Lett. 2019, 52, 511-525. [CrossRef]

42. Li, X.; Row, K.H. Application of novel ternary deep eutectic solvents as a functional monomer in molecularly imprinted polymers for purification of levofloxacin. J. Chromatogr. B 2017, 1068, 56-63. [CrossRef] [PubMed]

43. Li, X.; Row, K.H. Purification of antibiotics from the millet extract using hybrid molecularly imprinted polymers based on deep eutectic solvents. RSC Adv. 2017, 7, 16997-17004. [CrossRef]

44. Meng, J.; Wang, X. Microextraction by Packed Molecularly Imprinted Polymer Combined Ultra-High-Performance Liquid Chromatography for the Determination of Levofloxacin in Human Plasma. J. Chem. 2019, 2019, 1-9. [CrossRef]

45. Li, G.; Tang, W.; Cao, W.; Wang, Q.; Zhu, T. Molecularly imprinted polymers combination with deep eutectic solvents for solid-phase extraction of caffeic acid from hawthorn. Chin. J. Chromatogr. 2015, 33, 792-798. [CrossRef]

46. Ge, Y.-H.; Shu, H.; Xu, X.-Y.; Guo, P.-Q.; Liu, R.-L.; Luo, Z.-M.; Chang, C.; Fu, Q. Combined magnetic porous molecularly imprinted polymers and deep eutectic solvents for efficient and selective extraction of aristolochic acid I and II from rat urine. Mater. Sci. Eng. C 2019, 97, 650-657. [CrossRef]

47. Li, X.; Row, K.H. Preparation of deep eutectic solvent-based hexagonal boron nitride-molecularly imprinted polymer nanoparticles for solid phase extraction of flavonoids. Microchim. Acta 2019, 186, 753. [CrossRef]

48. Li, G.; Wang, X.; Row, K.H. Magnetic solid-phase extraction with Fe3O4/molecularly imprinted polymers modified by deep eutectic solvents and ionic liquids for the rapid purification of alkaloid isomers (theobromine and theophylline) from green tea. Molecules 2017, 22, 1061. [CrossRef]

49. Li, G.; Row, K.H. Ternary deep eutectic solvent magnetic molecularly imprinted polymers for the dispersive magnetic solid-phase microextraction of green tea. J. Sep. Sci. 2018, 41, 3424-3431. [CrossRef]

50. Tang, W.; Gao, F.; Duan, Y.; Zhu, T.; Ho Row, K. Exploration of deep eutectic solvent-based molecularly imprinted polymers as solid-phase extraction sorbents for screening chloramphenicol in milk. J. Chrom. Sci. 2017, 55, 654-661. [CrossRef]

51. Li, G.; Zhu, T.; Row, K.H. Deep eutectic solvents for the purification of chloromycetin and thiamphenicol from milk. J. Sep. Sci. 2017, 40, 625-634. [CrossRef]

(C) 2020 by the authors. Licensee MDPI, Basel, Switzerland. This article is an open access article distributed under the terms and conditions of the Creative Commons Attribution (CC BY) license (http://creativecommons.org/licenses/by/4.0/). 